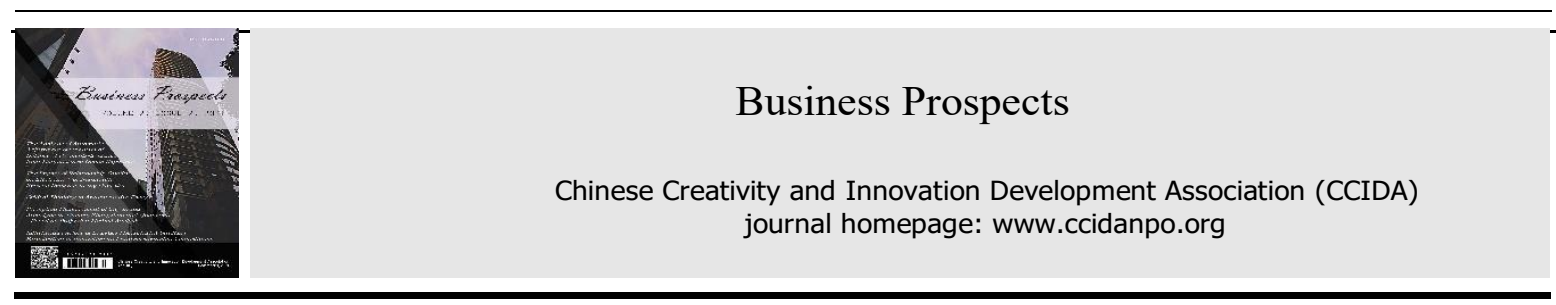

https://doi.org/10.52288/bp.27089851.2021.12.13

\title{
A Glimpse at the Study of English Neologism
}

\author{
Yan-Qing Fang 1,* \\ ${ }^{1}$ Associate Professor of School of the English Language and Culture, Xiamen University Tan Kah Kee College \\ * Correspondence: 247682022@qq.com
}

Received: 2021.07.22; Accepted: 2021.10.01; Published: 2021.12.01

\begin{abstract}
Language is a social phenomenon and changes with the development of society. Neologisms are new words and new expressions which are the cutting edge of language. Neologisms are being invented or introduced every day to express new things and new ideas in society. Scholars usually discuss neologisms from two perspectives: the time perspective and the semantic perspective. Neologisms can be classified according to their functions, their coinage processes, their formation, and their sources. There are three main methods of new word creation: neologisms by rules of word-formation; neologisms by adding new meanings to existing words; neologisms by borrowing words from other languages. Even a single method is quite productive in new word creation.
\end{abstract}

Keywords: English Neologism; Classification of Neologism; Formation of English Neologisms

\section{Introduction}

Neologisms are new words and new expressions; they are the cutting edge of language. Language is a social phenomenon and changes with the development of society. Among the three language elements, pronunciation and grammar are relatively stable and vocabulary is sensitive to social changes. Across the world, great changes have also taken place in political, economic and cultural fields. The rapid development in science and technology is most striking. Neologisms are being invented or introduced every day to express new things and new ideas in society. Never before in history has the world seen such an overwhelming onslaught of English neologisms. It is estimated that English vocabulary is increasing by at least 850 new words each year. Therefore, neologism is a very important part of English language. This paper attempts to analyze basic concepts of English neologisms through the following parts: Brief Research Background of English Neologism; Definition and Classification of English Neologism; and The Formation of English Neologisms (through Word-formation, by adding new meanings to existing words, and by borrowing words from foreign languages).

\section{Brief Research Background of English Neologism}

Early in the 1930s, the first dictionary of neologisms had been compiled. American linguist Dwight Bolinger was the earliest scholar who began to introduce English neologisms in periodicals in sequence. He created a column Living Language in Words (published in Los Angeles) between1937 and 1940. In 1943, his column appeared in American Speech and he renamed it Among the New Words. This column has been dedicated to collecting the latest new words since then.

War is the beds of neologisms. Since the Second World War, quiet many dictionaries and books about new words came into being. Bu tit was in the 1970s when technology began to develop quickly that the study of neologisms began to catch the public attention. Many columnists began to write articles about new words and some famous dictionaries like Oxford English Dictionary (OED) began to publish their supplements.

The recent twenty years have witnessed a new era of the compilation of dictionaries of neologisms. More than twenty such dictionaries came into being, which place stress either on the academic aspects, or on the popular aspects, or on both aspects. The Oxford University Press published its first edition Oxford Dictionary of New Words (ODIVI) in 1991, and then in 1997 a new edition appeared. From the mid-1990s, the development of the Internet has quickened the renewal of famous dictionaries. Many publishers take advantage 
of the Internet to establish their own websites and invite readers to participate in the collection and discussion of neologisms. Contrasted to the compiling of new words dictionaries, the number of related works and articles is limited. In some quarterlies about language, we can find some articles about neologisms.

\section{Definition and Classification of Neologism}

\subsection{Definition}

What is neologism?

What kind of word can be defined as "neologism"?

Could an old word with new sense be classified as neologism?

Actually, the researches on these questions are being heatedly pursued, yet no general agreement has been reached. Researchers with different knowledge backgrounds may define neologism in different ways. Neologisms are by definition "new", and as such are often directly attributable to a specific individual, publication, period, or event. The term "neologism" was itself coined around 1800. In linguistics, a neologism is a word, a term, or a phrase, which has been recently created ("coined")-often to apply to new concepts, or to reshape older terms in newer language form. The concept neologism has wide connotation, including word, new word group, new sense, new usage, new affixation and its derivation, old affixation with new usage and its derivation. They are also called vogue words, namely new and popular words.

Scholars usually discuss neologisms from two perspectives: the time perspective and the semantic perspective. From the time perspective, neologisms refer to words within a certain period. If those words, say appeared 20 or 30 years ago, are still used today, and have deeply rooted in people's minds, they can still hold the identity of neologism. From the semantic perspective, neologisms refer to words that newly appear in communication and carry the new meanings. However, those old words that hold the new meaning are also considered as neologisms.

So far, a general criterion for defining neologisms can be found:

1) Neologisms are the words, which didn't occur before and are newly built and currently enter the common lexicons.

2) Neologisms are the words, which within a certain period of time, have been widely, accepted by people and still find their applications nowadays.

3) Neologisms are those old words, which carry the new meanings.

In this paper, the terms neologisms and new words are used alternatively with the same reference, that is, the term 'new words' in this paper is only used to refer to neologisms, not in the sense of "words one does not know".

\subsection{The Classification of English Neologism}

Up till now, the English vocabulary has surpassed the number of 500,000 words with jargons excluded. According to the statistics of The Barnhart Dictionary Companion, there are 1,500 to 1,600 words and meanings inputting into the computer database each year (Wang, 1997).

Classification of neologisms in this paper is made according to the following four standards:

1) Neologisms can be classified according to their functions. Innumerable neologisms can be classified as either referential or expressive.

(a) Referential neologisms are neologisms created to fill the gap in a specific special field. They are produced to solve communication difficulties. For example, "core dump" (to clear out a computer's memory).

(b) Expressive neologisms are neologisms developed to introduce new forms of expression into discourse. For example, "open collar workers" (people who work at home or telecommute).

2) Neologisms can be classified according to their coinage processes.

(a) New words and expressions coming from old words and expressions but with new meanings. For example, "outing" (the practice of forcing lesbian and gay celebrities'out of the closet') and "killer" (adj, very cool, powerful).

(b) New created words and expressions, which are invented to describe new ideas and things. For example, "internet", "I-way" (short form of information superhighway).

(c) Borrowed words and expressions. For example, "masterpiece", "Mao-tai", and "man". 
3) Neologism can be classified according to their formation.

(a) Neologisms in form, including the following structures: derivations (with prefixes and suffixes); compounds; phrases; shortenings (using initialisms, acronyms, clippings). For example, "Pekingology", "educationese" and "hard science".

(b) Semantic neologisms, including three types of processes: Broadening or narrowing or change the meaning of the base forms. For example: "feedback" and "window".

(c) Borrowed neologisms, which are true borrowings and loan translations. For example: "masterpiece" and "perestroika".

4) Neologisms can be classified according to their sources, that is, according to where they come from:

(a) Scientific words or phrases created to describe new scientific discoveries or inventions. Examples: "Bluetooth", "Broadband network", "IW", and "Melatonin".

(b) Political words or phrases created to make political or rhetorical point, sometimes perhaps with an eye to the Sapir-Whorf hypothesis. Example: "Blairism", "Theoterrorism", "Humanitarian Crisis", "Jihad", "Kamikaze Attack".

(c) Pop-culture words or phrases evolved from mass media content or used to describe popular culture phenomena (these may be considered a subsection of slang). Examples:

Baldwin-a good-looking man, such as one of the Baldwin family of actors

Scooby Gang-a group that humorously resembles the teens on the cartoon

(d) Imported words or phrases originating in another language. Typically, they are used to express ideas that have no equivalent term in the native language. Examples: "Ginseng" (Chinese), "Sampam" (Chinese), "Yogurt" (Turkish).

(e) Trademarks are often neologisms to ensure they are distinguished from other brands. If legal trademark protection is lost, the neologism may enter the language as a generic zed trademark. Examples: "Kodak", "Coke", "Zipper", "Reebok", "Xerox", and "Apple writer".

(f) Nonce words, which are coined and used only for a particular occasion, usually for a special literary fact. For example: "AtomsFear", "Paradessence", "Plaino".

(g) Inverted words that are derived from spelling (and pronouncing) a standard word backwards. Example: "redrum".

(h) Paleologism that is alleged to be a neologism but turns out to be a long-used (if obscure) word which is used ironically.

The classification of neologisms will facilitate understanding of their meanings and at the same time give a very clear idea about how to use them in daily English.

\section{The Formation of English Neologisms}

According to Algeo (1991), there are six basic etymological sources for English new words: creating, borrowing, combining, shortening, blending and shifting. Each of those six sources, however, has a number of important subtypes. In addition to the major six sources, there are some other types of incomplete etymology. Here, to simplify the matter, the author attributes the new words to three sources: by creating new words through word formation processes, by adding new meanings to the existing words, and by borrowing words from foreign languages.

In order to show clearly the sources of neologisms in English, the author has made a survey based on "A Supplement to The English Chinese Dictionary SECD" edited by Lu (1999). The samples are taken every fifth page. The results come as Table 1 .

Table 1. Sources of Neologisms in English in SECD.

\begin{tabular}{ccc}
\hline Word Sources & Frequencies & Percentages \\
\hline Borrowing & 17 & $3.2 \%$ \\
Creating & 474 & $89 \%$ \\
Semantic Change & 40 & $7.5 \%$ \\
\hline
\end{tabular}

Table 1 indicates that creating neologisms through word formation becomes the major force at work. Adding new meanings to old words plays the second most important role. Borrowing plays the least important role. In this part, these three sources will be explored. 


\subsection{Creating Neologisms through Word Formation}

Creating neologisms means creating words based on native word elements such as letters, sounds, morphemes, roots, affixes, bases, and words. Usually, native speakers can easily understand a new word. This ability derives in part from the fact that there is a lot of regularity in word formation of a language. In this section, some basic word formation processes are explored by which new words are created in English.

\section{1) Compounding}

In English, compounding is the formation of new words by combining two or more bases. It has been a source of new words in English since the earliest times, and is still a productive way to create new words in present-day English. New words formed in this way are called compounds. English compounds are written in three ways: hyphenated, solid, or open. For example, easy-listening, superhighway, emotional quotient are all compounds. English compounds may be made up of more than two words such as electronic whiteboard, directto-consumer, golden handcuffs, stay-at home, cold dark matter, and back to-the -basics.

\section{2) Shortening}

In English, shortening is the formation of new words by omitting part of an old - word. The range of English shortening is flexible. In a narrow sense, it only refers to acronym; in a broad sense, it may include clipping, blending and even backformation. Here I use it to refer to blending, clipping, and acronym in English.

\section{a) Acronym}

Acronym is a process of forming new words by joining the initial letters of different words. Words formed in this way are called initialisms or acronyms, depending on the pronunciation of the words.

Initialisms are words formed from the initial letters of words and pronounced letter by letter. Letters may represent full words, for example: BBS (bulletin board system), CALL (computer-assisted language learning), and PWA (person with AIDS).

Acronyms are words formed from the initial letters of words and pronounced as words such as CEPA (Closer Economic Partnership Agreement), SARS (severe acute respiratory syndrome), DEWK (dual employed, with kids). Letters may represent all constituents in a compound or just parts of a word, for example, DVD (digital videodisc), and APEC (Asian Pacific Economic Cooperation Forum).

\section{b) Clipping}

Clipping is the simplest form of shortening by cutting a part of the original and using what remains instead. The clipped part may be the front, or the back or both the front and back, or the middle part of a word. Front clipping examples are mobile (automobile), Net (Internet), bot (robot), while app (application program), cell (cellphone), and expo (exposition) are back clipping examples. Front and back clipping examples are script (prescription), and shrink (headshrinker).

In modem times, people tend to be economical in writing and speech to keep up with the fast tempo of the new life style. To save time one is likely to clip words that are frequently used. They are frequent in informal language, especially in spoken language, as in the campus use of gym, econ, and grad for gymnasium, economics, and graduate respectively. Most of them preserve a colloquial flavor and are limited to the special vocabularies of occupational people, such as admin, app, demo, and droid, which are used for administrator, application program, demonstration, and android. And circulate very popularly among the young IT technicians in Silicon Valley.

c) Blending

Blending is a process in which clipping and combining occur simultaneously. A blend is a word made by joining two or more forms but omitting at last part of one, for example, cobot (cooperative robot), smist (smoke + mist), digiverse (digital + universe) etc.

In the past, blends were regarded as crack jokes. With time passing, new words produced by blending got to be accepted in writing related to newspapers and magazines, and in most times lost their humor, e.g., Interpol (international police), autoindustry (automobile industry), infowar (information + war), Siliwood (Silicon + Hollywood). Because blends are economic and simple in form, they are also used widely in science and technology. For example, biorhythm (biological + rhythm), lidar (light + radar), and pragmatic (programme + automatic). 


\section{3) Affixation}

As a way of forming new words, affixation means adding derivational affixes to bases to supply grammatical or lexical information in English. Affixation has played an active part in the development of the English language. According to the position affixes occupy in words, affixation falls into two subclasses: prefixation and suffixation. Prefixation is the formation of new words by adding prefixes to the beginning of bases, with, or without a change of word class, while suffixation is the other kind of formation of new words by adding suffixes to the end of a base, with, or without a change of word-class.

Nowadays, affixation still retains a vigorous capacity of production. There are hundreds of affixes in English, dozens of which are very active, for example, a-, be-, bi-, co-, con, counter-, de-, dis-, en-, in-, inter-, mis-, mufti-, non-, re-, un-, under-, and -er, -ability, -able, -cal, -acity, -al, -ism, -dom, -ee, -ed, -en, -ible, and so on. Besides these traditional affixes new ones are constantly produced, for example, cyber-, eco-, e-, -gate, nik, -vine, fest, -meister.

This process allows us to expand our vocabulary without specifically memorizing new words. For example, cyber-: With the invasion of computers in every sphere of life, words like cyberspace, cyber-romance and cybersex came into being. Cyberspace is the virtual reality or the imagined place where electronic data goes, a notional realm. With reference to the meaning of cyberspace, neologisms such ascybersurfer; cyberterrorism, cyberwill, cyberchat, cyberbabble, cyberacquaintance, cybercop, cybercritic, cybersoap, and cybersale are selfexplanatory.

\section{4) Conversion}

Conversion is the formation of new words by converting words of one class to another class. Words created in this way do not change in morphological structure, and they are new only in a grammatical sense, so this process is also known as a functional shift. Types of conversion mainly involve three major word-classes: nouns, verbs, and adjectives in English,

In English, conversion is a traditional word formation process throughout the history of the English language. In today's English it is still very common. The conversion that takes place between nouns and verbs is most productive. For instance. Sample is a noun, meaning "a small part of song from a CD or record that is used in a new song", e.g., "His latest album makes extensive use of samples from a wide range of acid jams tracks." Sample is converted to a verb, meaning "to use a small part of song from a CD or record in a new song", e.g., "His songs have often sampled by other people." (Longman Dictionary of Contemporary English 2002)

There are many such examples as archive (n - v), birth (n v), guilt (n-v), interface (n- -v), canyon (n*v), bookmark $(n--v)$, ramp $(n \cdot v)$.

$\mathrm{Lu}$ (1999) points out that now besides the simple words, even compounds can get shifted. For example, focus group is a noun, meaning "a panel of 'typical people' questioned by marked researchers or pollsters in order to learn the reactions and feelings of those questioned about subjects of interests to the questioners", e.g., "Ken was to the very end his own man, contemptuous of the spinners and focus groups." Now it can be used as a verb, meaning "to organize a focus group to discuss", e.g., "At least that's the conclusion of seven days of deliberating, brainstorming and focus grouping-all to pick a name for Bill Clinton's new pet." It can even be used as an adjective, e.g., "They are empty words, focus group words."

It deserves noting that conversion is not only a change of grammatical function of the item involved but also with it the different change of meaning it originally carries. For example, "It is surprising that more and more small companies are hoteling." Here, hotel means "to use the office on a part-time, reserved basis, rather than to have a permanently assigned office". Conversion may also take place between words of other parts of speech. For example, "There is no evidence of a collateral of agreement negativing the woman's indebtedness." Here negative is converted from an adjective to a verb.

\section{5) Other Minor Processes}

Besides the processes discussed above, there are also some other ways of creating new words in English.

Commonization of proper names is a very interesting source of English vocabulary. Common words coined from proper names may come from all sources, from names of scientists, politicians and statesmen and characters created in books to names of trademarks, places and books. For example, Xerox is the name of the corporation that produces a well-known photocopying machine, and much to the dismay of the company, this term has lost its specific brand-name connotation and has come to be used to describe the process of photocopying in general. It can be used as a noun or a verb.

Zhang (2002) mentions that among English new words, there are many communized proper names. For 
instance, Borg is a character from the film Star Trek and now it is used to refer to the most influential person in a specific field, e.g. "There is a widely circulated image of Bill Gates as a Borg in the software industry".

Backformation is a process of word-formation by which a word is created by the deletion of a supposed affix. It is the opposite process of affixation. As we know; affixation is the formation of new words by adding prefixes or suffixes to bases, therefore backformation is the method of creating new words by removing the imagined suffixes or prefixes. New words created through backformation are mostly verbs. For example, it is a common practice to add -er, -or, -ar, -(a) tion, -ing, to verbal bases to form nouns. Reasonably, people make verbs by dropping these endings in nouns such as bag from bagger; inform ate from information, jack from carjacking, abort from abortion. Words of other speech parts may be also back formed, such as flake from flaky, exolete from expletive, cathart from cathartic, intuit from intuition. Stylistically, back formed words are largely informal and some backformations are not fully accepted into formal English. For example, self-destruct is less formal than self-destroy.

Onomatopoeia is to create words, which sound like their referents. They may be the imitation of sounds made by their referents. For example, vroom is an echoic sound denoting any of the sounds made by a motor vehicle in accelerating or as an intransitive verb, meaning "to make or move off with such sounds", as in "He vroomed along the road." Other examples are zap expressing the sound made by or as if by a gun, and bleep, a short high- pitched sound, as if from electronic equipment. Resorting to homophone may create onomatopoeic words. Homophone is to replace a word with another which sounds the same, but different in spelling, meaning, etc. for example, F2F (face to face). Homophones are very common in netspeak. As the Internet is becoming part of people life, some such netspeak words are becoming popular. For example, C2C (client to client), B2C (business to client) and P2P (peer to peer).

\subsection{Adding New Meanings to the Existing Words}

Although newly-created words are especially striking, it must not be forgotten that old-established ones often take on additional shades of meaning as a result of extended technical knowledge or a changed point of view resulting from scientific or sociological causes. About 15 percent of new words are simply old words with new meanings. Actually, old words putting on new meanings are a common phenomenon in language. It is the direct result of the development of language. Things are changing in our modern world and words, the spokesmen of our time, subsequently keep the same pace with this trend. The words, which were used, previously may now carry a fresh meaning and stand for a new thing. They will increase both in the number and in the range as well.

In recent times, we have seen spin taking on a new political meaning, while web and dot have new uses in computer contexts. A great deal of language change, perhaps most, involves the development of completely new meanings of existing words, such as here:

Leggings, (noun) 1) women's tight trousers without a zip, which stretch to fit the shape of your body; 2) trousers worn to protect your legs. In the last edition of the Longman Dictionary of Contemporary English, sense 2) of leggings was the only one represented.

Horny (adj) 1) made of a hard substance, such as horn; 2) skin that is horny is hard and rough; 3) informal sexually excited; feeling horny; 4) informal, sexually attractive. The third sense of horny entered British English form American English some time ago; the fourth is new, and used by young people.

Buddy (noun) 1) informal, a fried; 2) AmE spoken, used to speak to a man you do not know; 3) someone who offers to look after and become a friend to a person who has AIDS. The third meaning is very specific, and shows the process of new vocabulary being generated to describe a way of helping AIDS sufferers. New meanings are not nesrs out of fesh words, Existing words can spit par, in a process known as lyrig. New layer of meaning grows up along with eistingiones, such as client (a computer on a network that recies information from a servyer), or brother (a word meaning a black man, used especially by other black men).

\subsection{New Words Borrowed from Other Languages}

English has shown a remarkable tendency to go outside its own linguistic resources and borrow from other language. English is famous for swallowing words which are from other languages. In the book, An Outline History of the English Language, Frederich T. Wood says, "English has borrowed from practically every 
language under the sun." Just because of its extensive and heavy borrowings, the English language is now endowed with an extremely rich and heterogeneous vocabulary. Estimated at more than a million words, English supposedly has the most copious vocabulary among all the languages in the world.

When we borrow words from French, they look more at home. That is because speakers of French ruled England for nearly four hundred years. As a result, French is the language that has been the most generous in bequeathing words to English. Nearly half of our present-day vocabulary (including the words language, generous, present, and of course vocabulary) comes from French. Down to the present day, English speakers have continued to borrow words from French, everything from prairie (1773) to entrepreneur (1852), elan (1880), decoupage (1960), and bustler (1979).

We still borrow, but today only about 5 percent of our new words are taken from other languages. They are especially prevalent in the names of foods: focaccia, salsa, vindaloo, ramen. Many times, the new words come along with the new item, such asspaghetti (Italian), camel (Hebrew), and chocolate (Mexican-India by way of Spanish), Ketchup (sometimes spelled catsup which comes from the Chinese sauce pronounced "ketsiap"). Besides French and German, English language also borrows words from many other languages. For example, alcohol (Arabic), boss (Dutch), pretzel (German), and zebra (Bantu), ranch (Spanish).

\section{Conclusion}

Never before in history has the world seen such an overwhelming onslaught of English neologisms to learn. The English language absorbs, rejects, and adapts elements of vocabulary as it goes along. It constantly renews itself by borrowing, coining, and combining words to express new ideas and new developments, and that process has never been more apparent than in the 20th century and onward. Social and technological change, political and economic developments, new ways of working, leisure and sport fashion and popular music, medicine, psychology, ecology, and oven new types of crime all help to produce new words to express new ideas.

There are three main methods of new word creation: neologisms by rules of word-formation; neologisms by adding new meanings to existing words; neologisms by borrowing words from other languages. Even a single method is quite productive in new word creation.

This paper is just a tentative study of English neologisms. Therefore, it doubtless has imperfections due to the limited time and research competence Analysis of English neologisms from perspectives of other branches of linguistics such as pragmatics, sociolinguistics or stylistics shall be suggested in future investigation.

\section{References}

1. Algeo, J. (1991). 50 Years Among the New Words. New York: Cambridge University Press.

2. Longman English-Chinese Dictionary of Contemporary English (1988). Hongkong: Longman Group (Fareast) Ltd, 874.

3. Lu, G. S. (1999). A Supplement to The English-Chinese Dictionary. Shanghai: Shanghai Translation Publishing House.

4. Wang, R. P. (1997). The Latest Development of English Vocabulary. Foreign Language Teaching and Research, 3: 39 $45+83$.

5. Zhang, Q. (2002). New American English. Beijing: Foreign Language Teaching and Researching Press.

(Editor: Jiaming Qiao) 